\title{
Aislamiento y caracterización de la cepa de Laetiporus cf. sulphureus, proveniente de plantaciones forestales de Eucalyptus globulus, del distrito de Yucay, Cusco, Perú
}

\section{Isolation and characterization of Laetiporus cf. sulphureus from forest plantations of Eucalyptus globulus, from the Yucay district, Cusco, Peru}

\author{
Mario Callalli Chancahuaña ${ }^{1,2}$ \& María E. Holgado-Rojas ${ }^{2,3}$
}

\author{
${ }^{1}$ Hongos Perú. Av. Ejército B-12, Cusco, Perú. Email: biomar6@gmail.com \\ ${ }^{2}$ Universidad Nacional de San Antonio Abad del Cusco, Av. De la Cultura 733 Cusco. Perú \\ ${ }^{3}$ Sociedad Botánica del Cusco. Av. De la Cultura 733 Cusco, Perú.
}

\section{Resumen}

Se realizó la colecta de Laetiporus cf. sulphureus a partir de troncos de Eucalyptus globulus L. en la localidad de Yucay durante los meses de febrero y marzo del 2014 con la finalidad de aislar y obtener la cepa de este poliporo cuyos basidiomas juveniles presentan propiedades alimenticias. Para la colecta se utilizó el método aleatorio simple, seleccionando aquellos que presentaban las mejores características en cuanto a tamaño, aspecto y textura, realizando el aislamiento a partir de un fragmento de pseudotejido en Agar Papa Dextrosa (PDA) y Agar Extracto Malta (EMA), a $25 \pm 1^{\circ} \mathrm{C}$ bajo condiciones de completa oscuridad. La caracterización macroscópica de la cepa se realizó en cuatro medios de cultivo PDA, EMA, HMA (Agar Harina de Maíz) y MBC (Medio Basado en Cerveza), incubados a 17, 21 y $25^{\circ} \mathrm{C}$, midiendo el diámetro de la colonia cada 24 horas durante siete días. Para la obtención de basidiomas el inoculo fúngico fue cultivado en sustrato lignocelulósico a base de aserrín de eucalipto en un 80\%. Las mejores características se lograron en la cepa L. sp-01, determinándose al HMA, EMA como los medios de cultivo más adecuados con 9.25 y 9.23 $\mathrm{mm} /$ día a $25^{\circ} \mathrm{C}$ respectivamente. Los cuerpos furctiferos se obtuvieron después de una incubación de seis meses e inmersión en agua a temperatura ambiente (shock térmico) por 24 horas.

Palabras clave. Caracterización, Cusco-Perú, Eucalyptus, Laetiporus, Xilófago.

\begin{abstract}
The collection of Laetiporus cf. sulphureus from Eucalyptus globulus L. in Yucay locality, was carried out during the months of February and March 2014 with the purpose of isolating and obtaining the strain of this polypore who's juvenile basidiomas have nutritional properties. For the collection, the simple random method was used, selecting those basidiomas that presented the best characteristics in terms of size, appearance and texture. The strain was isolated from a pseudo-tissue fragment by culturing on Potato Dextrose Agar (PDA) and Malt Extract Agar (EMA), at $25 \pm 1{ }^{\circ} \mathrm{C}$ under conditions of complete darkness. Subsequently, the macroscopic characterization of the strain was carried out in four culture media PDA, EMA, Corn Flour Agar (HMA) and Beer-Based Medium (MBC), incubated at 17, 21 and $25^{\circ} \mathrm{C}$, measuring the diameter of the colony every 24 hours for seven days. To obtain basidiomas, the fungal inoculum was cultured in $80 \%$ lignocellulosic substrate based on eucalyptus sawdust. The best characteristics were achieved in the L. sp-01 strain, determining HMA, EMA as the most suitable culture media with 9.25 and $9.23 \mathrm{~mm} /$ day at $25^{\circ} \mathrm{C}$ respectively. Fruiting bodies were obtained after a six-month of incubation and immersion in water at room temperature (thermal shock) for 24 hours.
\end{abstract}

Keywords. Characterization, Cusco-Peru, Eucalyptus, Laetiporus, Xilofago. 


\section{Introducción}

El cultivo de los hongos comestibles en la actualidad se ha presentado como una alternativa ideal para la obtención de alimentos sobre todo en países en vías de desarrollo, siendo fundamental en esta biotecnología el aislamiento y culturización de las especies reportadas como comestibles, donde la velocidad del crecimiento micelial es determinante para la elección de la cepa. (Lopez-Rodriguez et al., 2008). En países micofilicos como México esta actividad promueve beneficios económicos, ecológicos y sociales (Martínez-Carrera, 2002 ). Actualmente, la mayoría de las cepas utilizadas en el cultivo comercial provienen de regiones de América del Norte, Europa y el sur de Asia, las que son mantenidas bajo métodos convencionales para su preservación y utilización en investigaciones orientadas a su cultivo (Mata, Salmones, \& Gaitán-Hernández, 2010). Especies de Agaricus, Pleurotus, Lentinula y Ganoderma, se producen en mayor o menor grado en diversas partes del mundo (Chang \& Quimio, 1982). Otras especies menos conocidas son Neolentinus, Volvariella, Auricularia, Flammulina, Grifola, Hypsizigus, Lepista y Morchella (Martínez-Carrera, 2002; Mata et al., 2010). Flammulina mexicana Redhead, Estrada, \& Petersen en (Franco et al., 2012) entre los que se encuentra Laetiporus. Diversos autores han demostrado la capacidad de estos hongos para colonizar una gran variedad de sustratos lignocelulósicos, caracterizando las etapas de crecimiento micelial y producción de carpóforos.

Esta capacidad de colonización del sustrato depende de la calidad de cepa obtenida y principalmente la velocidad de crecimiento del micelio. Al respecto Holgado (2012) evalúa el crecimiento micelial de Pleurotus ostreatus y $P$. djamor en Medio Basado en Cerveza (MBC) con Tasas de crecimiento Diario (TCD) de 12,43 y 6,14 mm/día. Mientras que para Pycnoporus sanguineus (L: Fr) Murr. el medio EMA fue el más adecuado con una velocidad de crecimiento de $11.7 \mathrm{~mm} /$ día a $25^{\circ} \mathrm{C}$. (Bautista \& Sánchez, 2011). Lo que también se viene desarrollando en el CIPHAM de la UNSAAC.

Por lo que es necesario fortalecer el desarrollo de la fungicultura aplicando biotecnologías amigables con el ambiente como los residuos lignocelulósicos que se producen en la región como una alternativa agroecológica de desarrollo sostenible y la consecuente incorporación de nuevos alimentos en la dieta del poblador andino. De aquí la imperante necesidad de realizar estudios encaminados a la obtención, caracterización y aprovechamiento del germoplasma propio de la región, que generen técnicas adecuadas para la explotación masiva de los hongos comestibles, más aún si tomamos en cuenta que hasta ahora, se ha prestado poca atención a cepas de origen mesoandino, particularmente del orden de los poliporaceos.

Por consiguiente, evaluar el aislamiento y cultivo de Laetiporus cf.sulphureus, en diferentes medios de cultivo sólidos para obtener la cepa, permitirá que este hongo xilófago promisorio, sea considerado como un micorecurso nutraceutico cuyo estudio aún no se ha registrado en Perú.

\section{Materiales y Métodos}

\section{Área de estudio}

El ámbito de estudio comprende el distrito de Yucay que se encuentra a $2858 \mathrm{msnm}$ a 78 km. de la Ciudad del Cusco en el Valle Sagrado de los Incas. 
Cuyas coordenadas UTM corresponde a $13^{\circ} 19^{\prime} 10^{\prime} \mathrm{S}$ y $72^{\circ} 05^{\prime} 10^{\prime} \mathrm{W}$, limitando por el Norte con la provincia de Calca, por el Sur con el Distrito de Ollantaytambo, por el Este con el Distrito de Chinchero y por el oeste con la Comunidad de San Juan.

\section{Metodología}

\section{Obtención de basidiomas y determinación de los especímenes silvestres}

Los basidiomas fueron colectados por el método aleatorio simple seleccionando aquellos que presentan las mejores características en cuanto a tamaño, aspecto y textura (Mostajo, 2004), los cuales fueron extraídos de forofitos de E. globulus con la ayuda de una navaja estéril, en seguida colocados en frascos de vidrio estériles y transportados al Centro de Investigación y Producción de Hongos Alimenticios y Medicinales (CIPHAM), para sus posteriores evaluaciones.

Para la determinación de la especie se tomó en cuenta los caracteres macroscópicos y microscópicos, como la perennidad, tamaño del Píleo, coloración, forma de margen, consistencia, textura de la superficie, forma de los basidios, tamaño y forma de esporas, tipos de hifas, tipo de himenóforo y forma de poros. Asimismo, se utilizó bibliografía especializada, claves dicotómicas y consulta a especialistas.

\section{Aislamiento y obtención de cepas de Laetiporus cf. sulphureus, a partir de tejido vegetativo}

Se utilizó la metodología adaptada de Saldarriaga Osorio \& Pineda Gutiérrez (2001), los basidiomas fueron seleccionados tomando en cuenta el tamaño y el grado de desarrollo, prefiriendo los juveniles, los mismos que fueron desinfectados en una solución de hipoclorito de sodio al $0.5 \%$ durante 5 minutos. Se realizaron enjuagues con agua destilada estéril por tres veces. Luego se tomó una pequeña porción de pseudotejido (4-5 $\mathrm{mm}$ ) mediante cortes con bisturí de primer uso. Los fragmentos se colocaron en placas Petri con medios de cultivo: Agar Papa Dextrosa (PDA) y Agar Extracto Malta (EMA). La incubación se realizó a $25 \pm 1^{\circ} \mathrm{C}$, previa rotulación, observándose diariamente el crecimiento de hifas y la formación del micelio. Finalmente se obtuvo el micelio puro (cepa madre) realizando un repique a partir de las placas con las mejores características de crecimiento.

\section{Evaluación de la velocidad de crecimiento micelial}

Se tomó una pequeña fracción de la cepa madre (agar con micelio de $10 \mathrm{~mm}$ de diámetro) que se colocó en el centro de placas Petri con medios de cultivo: Agar Papa Dextrosa (PDA), Agar Extracto Malta (EMA), Agar Harina de Maíz (HMA) y Medio Basado en Cerveza (MBC), los cuales fueron incubados a 17,21 y $25^{\circ} \mathrm{C}$ midiéndose el crecimiento micelial durante 7 días con la ayuda de un vernier. La velocidad de crecimiento se calculó con la fórmula utilizada por Huerta, MartínezCarrera, Sánchez y Leal-Lara (2009):

Velocidad crecimiento $=(\mathrm{Df}-\mathrm{Di}) /(\mathrm{Tf}-\mathrm{Ti})$

Dónde:

Df $=$ Diámetro final de crecimiento

Di $=$ Diámetro inicial de crecimiento

Tf-Ti = Días de crecimiento micelial 
Cultivo de Laetiporus cf. sulphureus.

Se utilizaron formulaciones de aserrín de eucalipto (E. globulus), suplementado con salvado de trigo (T. aestivum), tomando como referencia lo utilizado por diferentes autores para el cultivo de Ganoderma (Tabla 1).
- parámetros registrados por un termohigrómetro), oxigenación (ventilación natural, por ventanas) y horas de luz natural.

\section{Tratamiento Estadístico}

La determinación de la calidad del aislamiento se definió mediante el uso del análisis de tabla cruzada. En tanto para las velocidades de crecimiento se aplico ANOVA.

Tabla 1. Formulaciones de sustratos utilizados para fructificación de Ganoderma lucidum, adaptado para el cultivo de Laetiporus cf. sulphureus

\begin{tabular}{lllcll}
\hline Aserrín & Salvado & Suplemen to & CaSO4 2 H2O & H2O & Referencias \\
\hline $80 \%$ & $18 \%$ & sacarosa 1\% & $1 \%$ & $67 \%$ & Chen y Miles, 1996b \\
$80 \%$ & $20 \%$ & - & un poco & $70 \%$ & Hseu, 1993 \\
$78 \%$ & $20 \%$ & - & $2 \%$ & $*$ & Liu et al., 1990 \\
$75 \%$ & $25 \%$ & - & - & $*$ & Lu y Chang, 1975, \\
& & & $3 \%$ & $*$ & Quimio, 1986 \\
$87 \%$ & $10 \%$ & - & & $*$ & Tong y Chen, 1990 \\
$93,50 \%$ & $5 \%$ & MgSO40,2 $\%$ & - & & \\
\hline
\end{tabular}

Fuente: Chen(1999)

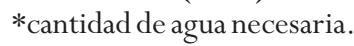

\section{Inoculación e incubación del sustrato} final

La inoculación se realizó en condiciones de asepsia, con un promedio de 30 gr. de spawn o inoculo fúngico para cada bolsa, conteniendo 1.5 kilogramos de sustrato previamente esterilizada. Durante la incubación se utilizaron ambientes cerrados a $25^{\circ} \mathrm{C} \pm 1$ sin iluminación (Deacon, 2006) hasta que los sustratos estuvieron completamente invadidos por el micelio. La inducción a la fructificación se realizó por inmersión en agua durante 24 horas (Stamets, 1993), a temperatura ambiente.

Monitoreo de los parámetros ambientales

Los parámetros a controlar fueron: la temperatura y la humedad que se mantuvo a través del riego diario por aspersión (ambos
La prueba de Tuckey para determinar el mejor medio de cultivo y la interacción. Los análisis estadísticos y gráficos fueron realizados mediante el uso del software de IBM-SPSS Statistics y Excel. Donde se plantea la hipótesis nula $\left(\mathrm{H}_{0}\right)$ todos los tratamientos tienen medias iguales, en tanto la hipótesis alterna $\left(\mathrm{H}_{1}\right)$, no todos los tratamientos tienen medias iguales.

\section{Resultados y discusión}

Descripción macroscópica y microscópica de Laetiporus cf. sulphureus

Basidioma, gregario, imbricado, anual, sésil, moderadamente adherido al sustrato, semicircular, hasta $18 \mathrm{~cm}$ de largo, $13 \mathrm{~cm}$ de ancho y $5 \mathrm{~cm}$ de altura. Superficie abhimenial: velutinosa finamente, lisa, glabra, de color naranja intenso, que al madurar se decolora bajando de intensidad, con margen lobulado de color amarillo azufre. Superficie himenial: 
finamente poroide, concoloro al margen que al ser manipuladas se torna de color café oscuro, con poros circulares. Contexto: carnosa, homogéneo de color blanco. Impronta: blanca. Sistema hifal: dimítico, hifas generativas de pared simple, delgada, hialinas, ramificadas, con septos simples; hifas esqueletales, hialinas, de pared simple. Basidios: hialinas de pared delgada, en forma de bate y/o clava, con el extremo proximal (base) delgado y el extremo distal (ápice) más ensanchada. Esporas: 3-5 um, hialinas, elipsoidales, de pared delgada, nucleadas. Hábitat: parásito, saprófito, lignícola, en plantaciones forestales sobre corteza y troncos de Eucalyptus globulus L. en pie y caídos (Fig. 1).

\section{Aislamiento a partir de pseudotejido}

La Tabla 2, muestra el grado de desarrollo del micelio a los siete días, en diferentes medios de cultivo observándose que todos los aislamientos resultaron positivos. Así las cepas L. sp-04, L. sp-05, L. sp-06 y L. sp-02 presentan crecimiento regular, L. sp-03 presenta crecimiento bueno, mientras L.sp-01 presenta un crecimiento excelente y mejores características de adaptación, el cual fue utilizado como cepa madre para las siguientes pruebas (Fig. 2, 3).

Tabla 2. Grado del desarrollo micelial de Laetiporus $\mathrm{cf}$. sulphureus, durante el aislamiento.

\begin{tabular}{clll}
\hline $\begin{array}{l}\text { Medio de } \\
\text { cultivo }\end{array}$ & Repeticiones & Código & $\begin{array}{l}\text { Crecimiento } \\
\text { micelial }\end{array}$ \\
\hline \multirow{2}{*}{ EMA } & A & L.sp-01 & +++ \\
& C & L.sp-02 & + \\
& L.sp-03 & ++ \\
\hline \multirow{2}{*}{ PDA } & A & L.sp-04 & + \\
& B & L.sp-05 & + \\
& C & L.sp-06 & + \\
\hline
\end{tabular}

+ : Regular, ++ : Buena, +++ : Excelente
La Tabla 3, muestra el recuento de los aislamientos positivos por cada medio de cultivo y la calidad del grado de desarrollo de las mismas, la que se determinó a través de datos cualitativos, siendo estas clasificadas en escala del 0 a 4, donde 0: no presenta crecimiento micelial, 1 : crecimiento regular, 2: crecimiento bueno y 3: crecimiento Excelente.

Tabla 3. Tabla cruzada de recuento y porcentaje esperado del medio de cultivo y crecimiento micelial.

\begin{tabular}{|c|c|c|c|c|c|}
\hline \multirow{2}{*}{$\begin{array}{l}\text { Medio } \\
\text { de } \\
\text { cultivo }\end{array}$} & & \multicolumn{3}{|c|}{ Crecimiento micelial } & \multirow{2}{*}{ Total } \\
\hline & & Regular & Buena & Excelente & \\
\hline \multirow[b]{2}{*}{ EMA } & Recuento & 1 & 1 & 1 & 3 \\
\hline & $\begin{array}{l}\% \text { del } \\
\text { total }\end{array}$ & 2.0 & 0.5 & 0.5 & 3.0 \\
\hline \multirow[b]{2}{*}{ PDA } & Recuento & 3 & 0 & 0 & 3 \\
\hline & $\begin{array}{l}\% \text { del } \\
\text { total }\end{array}$ & 2.0 & 0.5 & 0.5 & 3.0 \\
\hline \multirow[t]{2}{*}{ Total } & Recuento & 4 & 1 & 1 & 6 \\
\hline & $\begin{array}{l}\% \text { del } \\
\text { total }\end{array}$ & 4.0 & 1.0 & 1.0 & 6.0 \\
\hline
\end{tabular}

\section{Selección del medio de cultivo sólido} óptimo para la propagación del micelio vegetativo del hongo Laetiporus cf. sulphureus

El crecimiento micelial (Tabla 4 y Fig. 2) de la cepa L.sp.01, se evaluó a tres temperaturas distintas: $17^{\circ} \mathrm{C}, 21^{\circ} \mathrm{C}$ y $25^{\circ} \mathrm{C}$, en cuatro medios sólidos de cultivo: PDA, EMA, HMA y MBC, a través de una correlación entre las variables temperatura y medio de cultivo en relación el diámetro de crecimiento micelial, siendo este significativo.

Mediante el análisis de varianza (ANOVA) se corroboró las diferencias significativas en las medias para la variable medio de cultivo (Tabla 6) y temperatura (Tabla 7) encontrándose que ta velocidad de crecimiento micelial de L.sp-01 

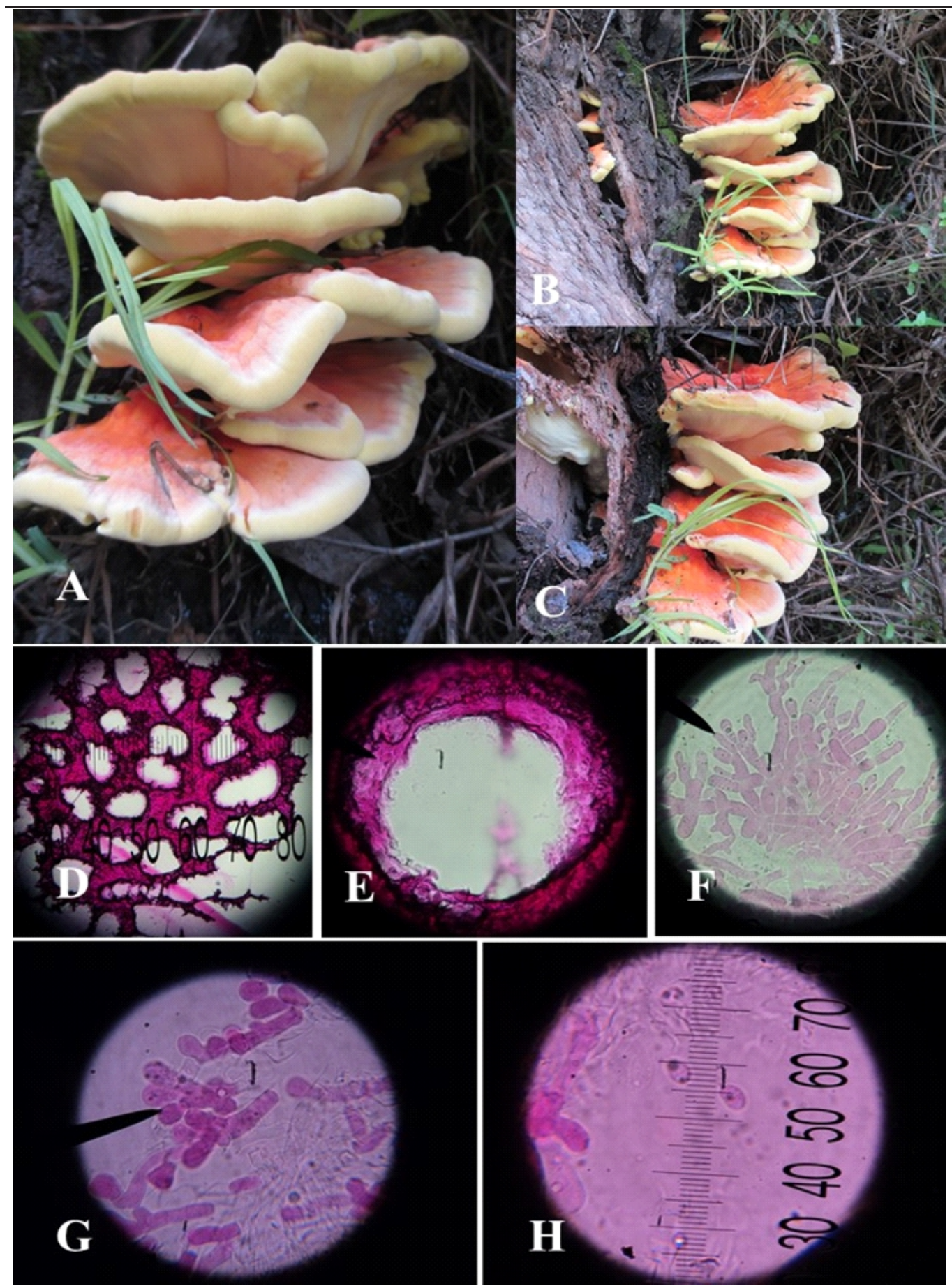

Figura 1. Laetiporus cf. sulphureus, A-C. Basidioma, D. corte transversal del himenóforo, E. poro, F. hifas, G. basidios y H. esporas, todas las estructuras microscópicas coloreadas con floxina. 
Tabla 4. Crecimiento micelial de L. sp-01, en cuatro medios de cultivo solido a tres temperaturas distintas.

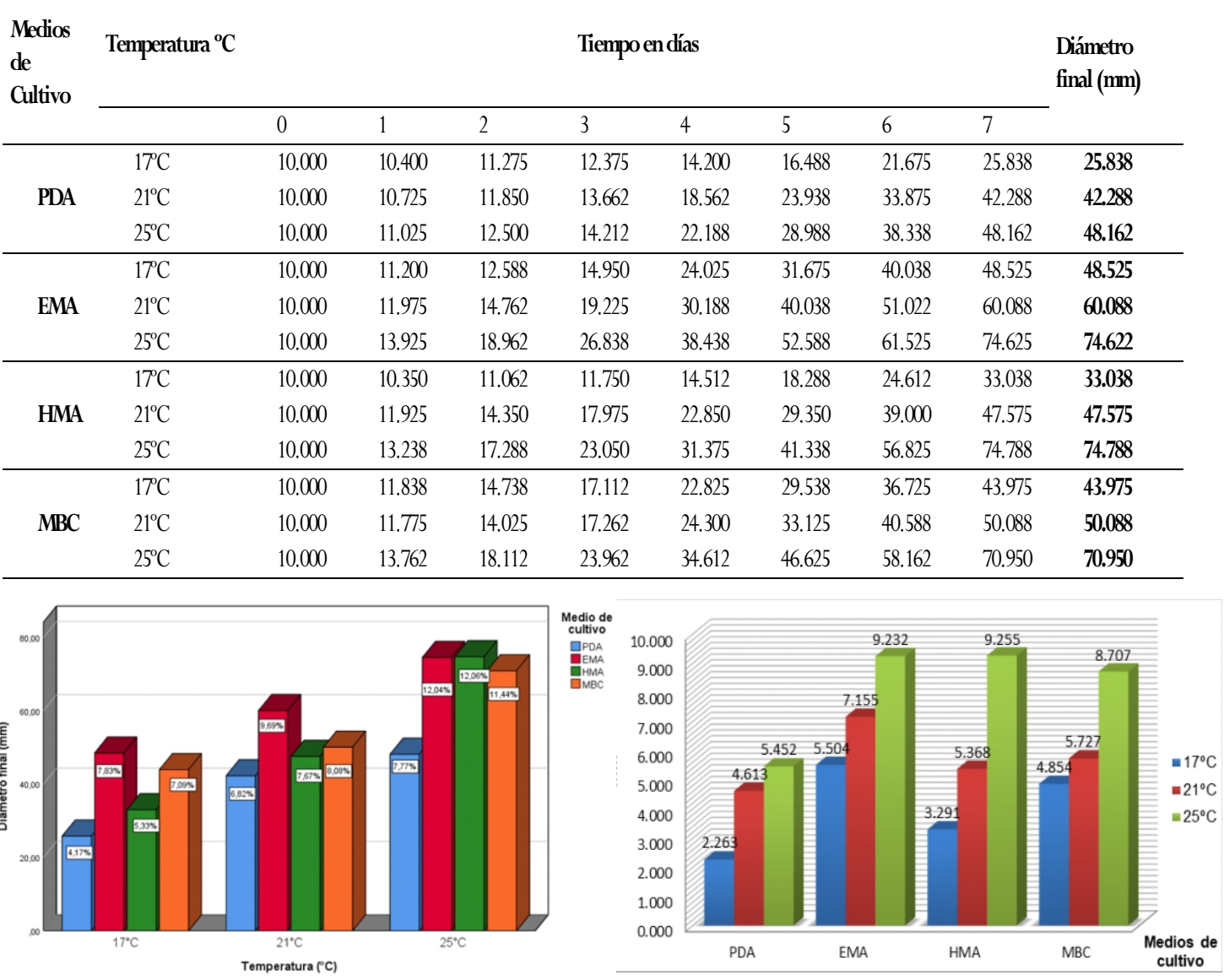

Figura 2. Crecimiento micelial de L.sp-01, en

Figura 3. Velocidad de crecimiento micelial cuatro medios de cultivo solido a tres temperaturas distintas (mm/ día) de L.sp-01, en cuatro medios de cultivo solido a tres temperaturas distintas.

Tabla6. Tabla de ANOVA del crecimiento micelial respecto al medio de cultivo

\begin{tabular}{lllll}
\hline Correlación & & $\begin{array}{l}\text { Medio de } \\
\text { cultivo }\end{array}$ & $\begin{array}{l}\text { Temperatura de } \\
\text { crecimiento } \\
\text { micelial }\end{array}$ & $\begin{array}{l}\text { Diámetro de } \\
\text { crecimiento } \\
\text { micelial }\end{array}$ \\
\hline Medio de cultivo & $\begin{array}{l}\text { Correlación de Pearson } \\
\text { Sig. (bilateral) }\end{array}$ & 1 &, 000 &, 294 \\
& $\mathrm{~N}$ & 12 & 1,000 &, 354 \\
Temperatura de crecimiento & Correlación de Pearson &, 000 & 12 & 12 \\
micelial & Sig. (bilateral) & 1,000 & 1 &, $796^{* *}$ \\
& $\mathrm{~N}$ & 12 & 12 &, 002 \\
Diámetro de crecimiento & Correlación de Pearson &, 294 &, $796^{* *}$ & 12 \\
micelial & Sig. (bilateral) &, 354 &, 002 & 1 \\
& $\mathrm{~N}$ & 12 & 12 & 12 \\
& & & & \\
\end{tabular}

\footnotetext{
**. La correlación es significativa en el nivel 0,01 (bilateral).
} 
Tabla 7. Tabla deANOVA del crecimiento micelial respecto a la temperatura

\begin{tabular}{lllllll}
\hline Variable & & SC & GL & MC & F & Sig. \\
\hline \multirow{3}{*}{ Temperatura } & $\begin{array}{l}\text { Entre } \mathrm{T}^{\circ} \mathrm{s} \\
\text { Dentro de } \\
\mathrm{T}^{\circ} \mathrm{s}\end{array}$ & 1731,557 & 2 & 865,779 & 7,991 &, 010 \\
\hline Total & & 975,147 & 9 & 108,350 & & \\
\hline
\end{tabular}

-es óptima a $25^{\circ} \mathrm{C}$ con $9.255 \mathrm{~mm} /$ día en HMA (Fig. 3) mostrando las mejores características en cuanto al desarrollo micelial, biomasa más algodonosa y la presencia de un halo bien definido. Los otros medios de cultivo también llegaron a invadir toda la placa Petri (Fig. 4), pero en mayor tiempo y con menor biomasa. Este aspecto es importante señalar ya que seleccionar el medio de cultivo óptimo para la propagación vegetativa nos permite conocer mejor la preferencia nutricional de la especie, de este modo se disminuye el tiempo de incubación de las placas y los resultados obtenidos serán tomados como antecedentes en el caso que se realice un proceso tanto de investigación y/o producción.

Numerosos trabajos se han realizado para evaluar la propagación del micelio vegetativo de hongos xilofagos silvestres y comerciales, entre ellos Bautista \& Sánchez (2011), determinan al medio de cultivo sólido Agar Extracto de Malta (EMA) como medio óptimo para Pycnoporus sanguineus, con una velocidad de crecimiento de $11.7 \mathrm{~mm} /$ día a $25^{\circ} \mathrm{C}$. En tanto que Holgado (2012), al evaluar el crecimiento micelial de Pleurotus ostreatus y P. djamor, determina como mejor medio de cultivo solido el Medio Basado en Cerveza (MBC) con una Tasa de crecimiento Diario (TCD) de 12,43 mm/dia y 6,14 $\mathrm{mm} /$ día, mientras que en el presente trabajo se determinó al Agar Harina de Maíz (HMA), como medio de cultivo óptimo para la propagación del micelio vegetativo con un crecimiento de $9.26 \mathrm{~mm} /$ día a $25^{\circ} \mathrm{C}$, siendo este último un agar casero a diferencia de las que usaron los autores anteriores que son comerciales, aminorando de esta manera los costos de este material de laboratorio indispensable para el cultivo y aumento de biomasa micelial.

\section{Monitoreo de los parámetros ambientales}

En el cultivo de hongos comestibles se deben tener en cuenta varios factores a la hora de producción, entre los más importantes, temperatura, humedad e iluminación, para que estos hongos puedan crecer de forma satisfactoria. Según Stamets (2005) la temperatura para el desarrollo del micelio debe ser $24^{\circ} \mathrm{C}$ hasta que invada completamente el sustrato y para la formación de primordios se requiere de un cambio brusco de temperatura que fluctué entre $10-15.6^{\circ} \mathrm{C}$ durante por lo menos 5 días, en la presente investigación se pudo ver que estos tiempos de shock térmico pueden ser menores, así para Laetiporus fue necesario solo 24 horas. En cuanto a la Humedad relativa la literatura reporta valores entre 60 y 95\% para la mayoría de las especies (Chang \& Hayes, 1987). 

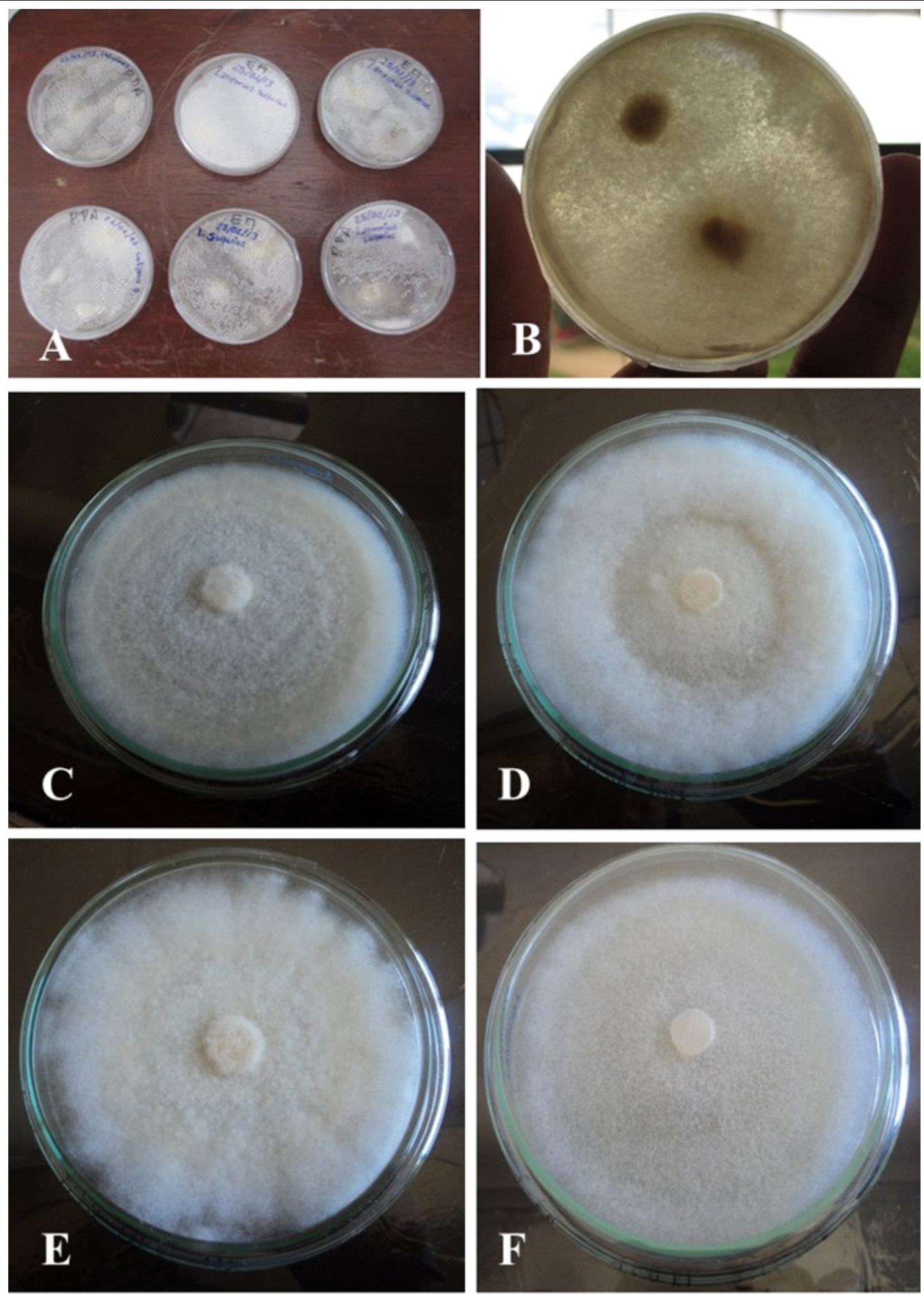

Figura 4. Desarrollo de crecimiento micelial vegetativo de L.sp-01 en medio de cultivo sólido. A: aislamiento de pseudotejido en PDA y EMA, B. L.sp-01, C. PDA, D. HMA, E. MBC y F. EMA. 

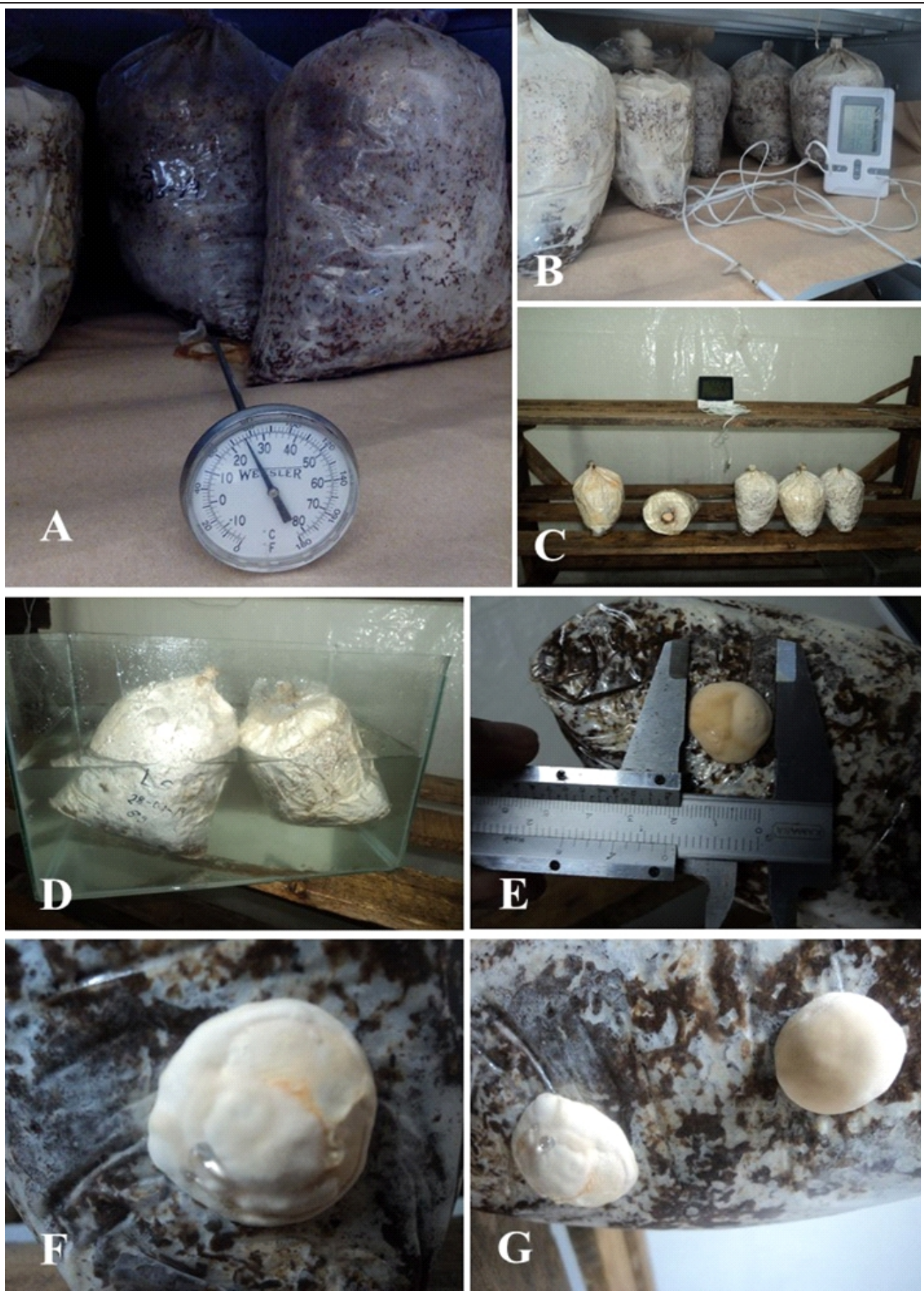

Figura 5. Obtención de los basidiomas de Laetiporus cf. sulphureus. A, B y C. monitoreo de los parámetros ambientales, D. shock térmico (inducción a fructificación), E, F y G. basioma (primordio) en aserrín de Eucalyptus globulus 1 . 
Los mismos autores mencionan que para Pleurotus ostreatus se ha observado que una humedad de $85-90 \%$ es la más adecuada ya que una inferior al $80 \%$ resulta negativa para la formación de los carpóforos. En el caso de Laetiporus, este parámetro se mantuvo casi constante entre los $89-90 \%$ con resultados satisfactorios (Tabla 8).

\section{Obtención de los basidiomas}

Se logró obtener primordios de Laetiporus $\mathrm{cf}$. sulphureus., en condiciones de laboratorio luego de 6 meses de incubación del sustrato utilizando aserrín de eucalipto (E.globulus L.) 80\%, salvado de trigo (T. aestivum) 18\%, sacarosa (azúcar comercial) $1 \%$, sulfato de calcio (CaSO4 $2 \mathrm{H} 2 \mathrm{O}$ ) $1 \%$ y aproximadamente $67 \%$ de agua. Semejante formulación utilizan Bautista \& Sánchez (2011), para la obtención de basidiomas de Pycnoporus sanguineus, con un 80 \% aserrín, $19 \%$ salvado de arroz y $1 \%$ de yeso, logrando la fructificación también después de 6 meses de incubación, valores que podríamos considerarlos como estándar para el cultivo de poliporaceos, siendo la única diferencia el tiempo de shock térmico que en nuestra investigación fue de solo 24 horas, mientras que para P.sanguineus fue necesario hasta tres días. Es importante señalar que los insumos usados (Aserrín de eucalipto, salvado de trigo) están siempre disponibles en la región.

La luz del día suele ser suficiente para obtener buenas fructificaciones y no se ha demostrado que iluminar más tiempo permita un mejor rendimiento (Arjona, Aragón, Aguilera, Ramírez, \& Pisabarro (2008). Durante la etapa de colonización del sustrato se debe trabajar bajo completa oscuridad, sin embargo, durante la fructificación la luz es necesaria de 8- 12 horas diarias. Es suficiente una luz que permita ver durante las horas diurnas para la formación de botones (García, 1991), así en la formación de los primordios de Laetiporus cf. sulphureus fue suficiente exponer los sustratos durante 3 días a las horas de luz natural del día (Fig. 5).

\section{Conclusiones}

Se aisló y caracterizo la cepa de Laetiporus cf. sulphureus a partir de pseudotejido, la cual fue codificada como L.sp-01, determinándose como medio de cultivo óptimo al Agar Harina Maíz (HMA) que presento mayor velocidad de crecimiento micelial respecto a los otros medios de cultivo convencionales. Los primordios se desarrollaron en sustratos a partir de aserrín de eucalipto (Eucalyptus globulus L.) $80 \%$, salvado de trigo (Triticum aestivum) 18\%, sacarosa (azúcar comercial) 1\%, sulfato de calcio $1 \%$ y aproximadamente $67 \%$ de agua, previamente sometidos a shock térmico durante 24 horas y tres días de exposición en luz natural.

\section{Agradecimientos}

Nuestro agradecimiento al M.Sc. Carlos A. Salvador Montoya por la bibliografía proporcionada, a los semilleros de investigación del Centro de Investigación de Hongos Alimenticios y Medicinales-CIPHAM por su contribución en la colecta de los basidiomas en campo, especialmente a Albino Quispe y Milton Callañaupa.

\section{Conflicto de intereses}

Los autores declaran no tener conflicto de intereses. 


\section{Literatura citada}

Arjona, D., Aragón, C., Aguilera, J. A., Ramírez, L. \& Pisabarro, J. (2008). Reproducible and controllable light induction of in fruiting of the whiterot basidiomycete Pleurotus ostreatus. Mycological Research (10). Navarra, España.

Bautista, N. \& Sánchez, P. (2011). Aislamiento y Cultivo del hongo Pycnoporus sanguineus (L: Fr) Murr. Para Evaluar la Actividad Leishmanicida en promastigotas de Leishmania. Tesis para optar al Título Profesional de Biólogo. Cusco-Perú.

Chang, S. T. \& Hayes, A. (1987). The biology and cultivation of edible mushrooms. The University of Chicago Press Journals. NuevaYork. EE.UU.

Chen,A. (1999). Cultivation of the medicinal mushroom Ganoderma lucidum (Curt.:Fr.) P. Karst.(Reishi). International Journal of medicinal mushrooms.

Deacon, J. (2006). Fungal Biology. Institute of Cell and Molecular Biology, University of Edinburgh, UK. Editorial Blackwell Publishing, cuarta edición.

Franco, M. S., Burrola-Aguilar C. \& Arana, G. Y. (2012). Hongos comestibles silvestres: Un recurso forestal no maderable del Nevado de Toluca. México: EON.

García, E. (1991). Cultivo de setas y trufas. Ed. Mundiprensa. Madrid España.

Hernández, R. \& López, C. (2005). Evaluación del crecimiento y producción de Pleurotus ostratus sobre diferentes residuos agroindustriales del departamento de Cundinamarca.

Holgado-Rojas, M. E. (2012). Cultivo de Pleurotus ostreatus (Jacq.ex Fr.) Kumm y Pleurotus djamor (Rumph. ex Fr.) Boedijn (Tricholomataceae) en la comunidad San Nicolásde Bari-Zurite-Anta. Tesis Maestría en Ciencias mención Ecología y Recursos Naturales EPG. UNSAAC.

Huerta, G., Martínez-Carrera, D., Sánchez, J. E. \& Leal-Lara, H. (2009). Grupos de interesterilidad y productividad de cepas de Pleurotus de regiones tropicales y subtropicales de México. Revista Mexicana de Micología, 30.

López-Rodriguez, C., Hernández-Corredor, R., Suárez-Franco, C. \& Borrero, M. (2008). Evaluación del crecimiento y producción de Pleurotus ostratus sobre diferentes residuos agroindustriales del departamento de Cudinamarca. Universitas Scientiarum.
Martínez-Carrera, D. (2002). Current development of mushroom biotechnology in Latin America. Micología Aplicada International, 14(2).

Mata, G., Salmones, D. \& Gaitán-Hernández. (2010). Basic and applied research on mushroom cultivation at the Institute of Ecology, Xalapa, México. In D. Martínez-Carrera, N. Curvetto, M. Sobal, P. Morales, \& V. M. Mora (Eds.), Hacia un desarrollo sostenible del sistema de producción-consumo de los hongos comestibles y medicinales en Latinoamérica: Avances y perspectivas en el siglo XXI México: Red Latinoamericana de Hongos Comestibles y Medicinales.

Mostajo, M. (2004). Aislamiento y evaluación de diversos sustratos para el crecimiento vegetativo del hongo Auricularia delicata (Fries) Henn del valle de la convención. Tesis para optar el grado de magister en ciencias con mención en Biología. Lima-Perú.

Saldarriaga, O, Y. \& Pineda, G. F. (2001). Manual de Micología Aplicada. Medellín, Colombia: Editorial Universidad de Antioquía.

Stamets, P. \& Chilton, J. S. (1993). Grain culture. En: "The Mushroom Cultivator". Editorial Agarikon. Washington.

Stamets, P. (2005). Growing gourmet and medicinal mushrooms. Third Edition. Toronto. 